\title{
Hypereosinophilic syndrome: considerations for the cardiologist
}

\author{
Antoine Bondue (10 , ${ }^{1}$ Caroline Carpentier, ${ }^{2}$ Florence Roufosse ${ }^{2}{ }^{2}$
}

'Department of Cardiology, Hopital Erasme and IRIBHM, Université Libre de Bruxelles, Brussels, Belgium

${ }^{2}$ Department of Internal Medicine, Hopital Erasme, Université Libre de Bruxelles, Brussels, Belgium

\section{Correspondence to} Dr Florence Roufosse, Internal Medicine, Erasmus Hospital, Bruxelles 1070, Belgium; froufoss@ulb.ac.be

Received 5 March 2021 Accepted 20 May 2021
Check for updates

(c) Author(s) (or their employer(s)) 2021. No commercial re-use. See rights and permissions. Published by BMJ.

To cite: Bondue $\mathrm{A}$ Carpentier C, Roufosse F. Heart Epub ahead of print: [please include Day Month Year]. doi:10.1136/ heartinl-2020-317202

\begin{abstract}
Eosinophil-mediated endomyocardial damage is a wellknown complication in patients with hypereosinophilic syndromes (HES). Although management and survival have improved significantly, some patients continue to develop severe cardiomyopathy as a direct consequence of uncontrolled hypereosinophilia. Cardiologists play a key role in early detection and treatment. At the early generally asymptomatic stage, related to subendocardial eosinophilic infiltrates, elevation of the biomarker of cardiac damage (serum troponin) and cardiac MRI are the best tools for diagnosis. As disease progresses, patients typically develop intracardiac mural thrombi and may experience variable degrees of heart failure due to valve damage and/or subendocardial fibrosis, all of which are more readily detectable with traditional echocardiographic investigation. New imaging modalities such as strain imaging and specific sequences in MRI offer the perspective of detecting subtle perturbations and distinguishing inflammatory versus fibrotic stages. Endomyocardial biopsy may help in difficult settings, namely, when blood eosinophilia is not prominent, but may be non-contributive due to sampling issues or eosinophil degranulation or replacement by fibrosis, and must always be performed after careful consideration of the risk:benefit ratio. Although treatment of the HES itself should be managed by clinicians with expertise in this rare disorder with the aim of lowering eosinophil counts to prevent and treat eosinophil-mediated organ damage and dysfunction, cardiologists play a key role in managing the associated cardiopathy. There are no consensual disease-specific guidelines for treating eosinophil-mediated thrombotic complications and cardiopathy, which should be managed according to classical international recommendations.
\end{abstract}

\section{INTRODUCTION}

Cardiologists have long been aware of and confronted with the deleterious effects of hypereosinophilia (HE) on the heart. Substantial progress has been made in the detection of these alterations at early stages and, in parallel, management of hypereosinophilic conditions has improved. Although this has resulted in decreased frequency and mortality of eosinophil-mediated cardiac complications, differential diagnosis of $\mathrm{HE}$ itself may still be delayed, and patients may have developed irreversible and/or life-threatening cardiomyopathy by the time they receive appropriate treatment. This review is intended to provide cardiologists with state-of-the-art knowledge for (1) determination of whether a patient with persistent HE has cardiac complications and (2) approaching diagnosis of an underlying hypereosinophilic disorder in a patient presenting with unexplained cardiomyopathy. Although a variety of clinical conditions associated with HE may potentially lead to eosinophil-mediated heart damage, we will focus on hypereosinophilic syndrome (HES).

\section{EOSINOPHILS, HYPEREOSINOPHILIA, HYPEREOSINOPHILIC SYNDROME, AND THE HEART}

Eosinophils are myeloid cells whose differentiation, proliferation and maturation are dependent on a specific set of transcription and growth factors, including interleukin-5. ${ }^{1}$ Once mature, eosinophils enter the circulation, then home to certain tissues, where they presumably contribute to homeostasis. In healthy subjects, eosinophils represent less than $5 \%$ of circulating leucocytes (absolute counts below $0.5 \mathrm{G} / \mathrm{L})$. In certain conditions, blood and/or tissue eosinophil counts are increased, and the term HE is appropriate when blood eosinophilia rises above $1.5 \mathrm{G} / \mathrm{L}$ and/or increased presence of eosinophils or their granule proteins is observed in tissue (table 1). Expansion of the eosinophilic lineage is observed in various situations through different mechanisms that may be neoplastic (primary), reactive (secondary) or unknown (idiopathic). ${ }^{2}$ In the large majority of cases, $\mathrm{HE}$ is reactive and occurs in the setting of an underlying illness such as a drug reaction, helminthic infection or cancer (table 2). In some cases, such causes are not detected, and if there is evidence of associated eosinophil-mediated tissue/organ damage or dysfunction, this defines a disease spectrum called HES (table 1). Patients with HES are classified on the basis of mechanisms responsible for eosinophilic expansion (table 1). ${ }^{1}$ Disease variants include neoplastic hypereosinophilic syndrome $\left(\mathrm{HES}_{\mathrm{N}}\right)$, reactive hypereosinophilic syndrome $\left(\mathrm{HES}_{\mathrm{R}}\right)$ and idiopathic HES. These entities require medical attention and treatment to control blood and tissue eosinophilia and reverse and/or prevent damage. Target organs typically include the skin, lungs, gastrointestinal tract, heart, vascular system, and both central and peripheral nervous systems. Occasionally, HE of unknown aetiology occurs in the complete absence of organ involvement; this condition is called $\mathrm{HE}$ of undetermined significance and does not require treatment.

\section{Epidemiology and impact of cardiac involvement in patients with HES}

Since the earliest descriptions of patients with HES, the heart has clearly emerged as a privileged target organ for eosinophil-mediated damage. In the first large retrospective review published in 1975, 95\% of patients had clinical evidence and/or autopsy findings of cardiopathy. ${ }^{3}$ Improved management of HES has reduced the occurrence of cardiac involvement, 


\begin{tabular}{|c|c|c|}
\hline Terms & Definition & Examples \\
\hline Eosinophilia & Absolute eosinophil count of $0.5-1.5 \mathrm{G} / \mathrm{L}$ & Atopic dermatitis, asthma \\
\hline HE & $\begin{array}{l}\text { Absolute blood eosinophil count of }>1.5 \mathrm{G} / \mathrm{L} \text { and/or } \\
\text { tissue eosinophilia considered excessive by pathologist and/or } \\
\text { presence in tissue of indirect evidence of eosinophil degranulation* }\end{array}$ & \\
\hline $\mathrm{HE}_{\mathrm{R}^{\prime}}$ secondary & $\begin{array}{l}\text { Polyclonal eosinophil expansion secondary to increased presence of } \\
\text { eosinophilopoietic factors (most often IL-5) }\end{array}$ & $\begin{array}{l}\text { Parasitic infection, allergic drug reactions, paraneoplasti } \\
\text { (lung cancer and T-cell lymphoma) }\end{array}$ \\
\hline $\mathrm{HE}_{\mathrm{N}^{\prime}}$ primary & $\begin{array}{l}\text { Clonal eosinophil expansion due to occurrence of a somatic mutation in } \\
\text { a haematopoietic/myeloid stem cell/precursor }\end{array}$ & $\begin{array}{l}\text { Chronic myelomonocytic leukaemia } \\
\text { Chronic myelogenous leukaemia }\end{array}$ \\
\hline $\mathrm{HE}_{\mathrm{us}}$ & $\begin{array}{l}\text { Cause of eosinophil expansion unknown and absence of detectable } \\
\text { complications despite persistent } \mathrm{HE} \text { and thorough investigations }\end{array}$ & \\
\hline HES & $\begin{array}{l}\text { 1. HE (as defined earlier). } \\
\text { 2. Presence of eosinophil-mediated organ damage/dysfunction. } \\
\text { 3. Absence of other explanations for observed damage. }\end{array}$ & \\
\hline $\mathrm{HES}_{\mathrm{R}}$ & $\begin{array}{l}\text { Polyclonal eosinophil expansion secondary to increased presence of } \\
\text { eosinophilopoietic factors (most often IL-5) }\end{array}$ & Lymphocytic variant HES \\
\hline $\mathrm{HES}_{\mathrm{N}}$ & $\begin{array}{l}\text { Clonal expansion of eosinophils: detection of a chromosomal } \\
\text { rearrangement, and/or increased blasts in blood/bone marrow }\end{array}$ & FIP1L1-PDGFRA ${ }^{+}$rearrangement \\
\hline Idiopathic & Aetiology of eosinophil expansion unknown & $\begin{array}{l}\text { Chronic eosinophilic pneumonia, eosinophilic } \\
\text { gastrointestinal disease, systemic (multiorgan) HES }\end{array}$ \\
\hline
\end{tabular}

*For example, deposition of granule proteins, Charcot Leyden Crystals, free granules.

$\mathrm{HE}$, hypereosinophilia; $\mathrm{HE}_{\mathrm{N}^{\prime}}$ neoplastic hypereosinophilia; $\mathrm{HE}_{\mathrm{R}^{\prime}}$ reactive hypereosinophilia; $\mathrm{HES}$, hypereosinophilic syndrome; $\mathrm{HES}_{\mathrm{N}^{\prime}}$ neoplastic hypereosinophilic syndrome; $\mathrm{HES}_{\mathrm{R}^{\prime}}$ reactive hypereosinophilic syndrome; $\mathrm{HE}_{\mathrm{us}}$, hypereosinophilia of undetermined significance; IL, interleukin.

as reflected by a more recent multicentre retrospective study reporting a frequency of less than $5 \%$ at presentation and $20 \%$ during the course of disease. ${ }^{4}$ Significant variability exists among cohorts, however, with roughly one-third of patients with HES $_{N}$ developing endomyocardial fibrosis, ${ }^{5}$ while patients with $\operatorname{HES}_{\mathrm{R}}$ practically never develop cardiac damage. ${ }^{6}$

Biological or clinical disease characteristics that place patients with HES at risk for development of cardiac damage remain elusive. The previous notion that male sex is a risk factor ${ }^{7}$ can now be explained by the overwhelming male predominance among patients with $\mathrm{HES}_{\mathrm{N}}{ }^{8}$ The association between higher peak eosinophil counts and cardiopathy ${ }^{9}$ is debatable as heart damage may occur at all levels of HE nor is there a clear relationship with the duration of HE. ${ }^{10}$

The development of eosinophil-mediated heart damage is a major determinant of prognosis in patients with HES that was often detected postmortem in early studies. ${ }^{3}$ Improved global outcomes since then have been largely due to earlier detection and management of cardiac complications, although they still accounted for one-third of deaths in the recent Mayo Clinic study of patients with HES. ${ }^{11}$

\section{Characteristics, natural course and pathogenesis of cardiac damage in HES}

Cardiac complications in HES typically develop in a stepwise manner, although overlap between successive phases may occur (figure 1). ${ }^{12}$ The earliest acute phase comprises eosinophilic infiltration of the subendocardium and is generally asymptomatic, although fulminant myocarditis may rarely occur with extensive necrosis and rapidly progressive HF. Cardiac tamponade may rarely develop in this setting. In the second stage, intracavitary (mostly ventricular) thrombi form, and patients are at risk of systemic embolisation. Over time, persistent eosinophilic inflammation leads to development of subendocardial fibrosis, especially in the trabecular region and inflow tracts, defining the third stage. Fibrosis may be diffuse (often several millimetres thick) and may result in restrictive cardiomyopathy with congestive HF. Endocardial inflammation and fibrosis may involve valves and/or their supporting structures with rupture of the chordae tendinae or fibrosis of papillary muscle. ${ }^{7}$ The pericardium may also be affected, mainly in the acute phase, and is generally associated with myocarditis (pancarditis) .

Histopathological studies of endomyocardial biopsies (EMBs) and autopsy material from patients with HES support a direct and major role for the eosinophil itself in the observed damage. ${ }^{12} 13$ Intracavitary thrombotic material contains numerous intact and degranulating eosinophils, as do the endocardium and myocardium, although they may be absent when fibrosis has developed and/or treatment has been initiated. When eosinophils are not detectable, demonstration of extracellular deposition of eosinophil-specific granule proteins indicates their recent presence. ${ }^{14}$ Mechanisms through which eosinophils impact endothelial cells (ECs), cardiomyocytes and coagulation pathways have been reviewed ${ }^{15}$ and are summarised in table 3 .

The presumed chain of events leading to end-stage heart disease in patients with HES begins with alterations of ECs lining the endocardium and capillaries within cardiac tissue. Endocardial damage favours thrombus formation, and eosinophil-rich thrombi represent a persistent and concentrated source of profibrotic eosinophil-derived mediators in close proximity to the subendocardium and adjacent myocardium.

\section{DETECTION OF EOSINOPHILIC CARDIAC INVOLVEMENT}

Detection of cardiac disease at early potentially reversible stages is a cornerstone in further improving HES patient outcomes. Patients are often asymptomatic at the early stages, however, underscoring the importance of thorough and repeated cardiac evaluation in all cases. Clinically, the presence of splinter haemorrhages is thought to reflect a propensity for EC damage in patients with $\mathrm{HE}$, and this sign should be taken very seriously. Advanced complications range from valvulopathy, thromboembolic disease, congestive heart failure (HF), myocardial ischaemia, arrhythmia and pericarditis. ${ }^{76}$ Sudden cardiac death due to ventricular arrhythmia or to massive pulmonary embolism can be the first disease manifestation. Importantly, there is no 
Table 2 Diseases associated with hypereosinophilia*

\begin{tabular}{|c|c|c|}
\hline Underlying disorders & & Examples \\
\hline \multicolumn{3}{|l|}{ COMMON } \\
\hline Infectious & $\begin{array}{l}\text { Parasitic: } \\
\text { multicellular } \\
\text { helminths with } \\
\text { phase of larval } \\
\text { migration in tissue }\end{array}$ & $\begin{array}{l}\text { Strongyloides stercoralis } \\
\text { Toxocara canis/catis } \\
\text { Trichinella spiralis } \\
\text { Ascaris lumbricoides }\end{array}$ \\
\hline
\end{tabular}

\begin{tabular}{|c|c|c|}
\hline & Ectoparasites & Scabies (Sarcoptes scabiei) \\
\hline & Fungal & $\begin{array}{l}\text { Allergic bronchopulmonary } \\
\text { aspergillosis }\end{array}$ \\
\hline & Viral & HIV \\
\hline \multirow[t]{2}{*}{ Allergic } & Severe atopy $\dagger$ & $\begin{array}{l}\text { Severe eosinophilic asthma } \\
\text { Severe atopic dermatitis }\end{array}$ \\
\hline & Drug reactions & $\begin{array}{l}\text { Classical drug-induced rash } \\
\text { Lung infiltrates } \\
\text { Drug reaction/rash with } \\
\text { eosinophilia and systemic } \\
\text { symptoms }\end{array}$ \\
\hline \multirow[t]{2}{*}{ Neoplastic } & Haematological & $\begin{array}{l}\text { TCL (angioimmunoblastic TCL, } \\
\text { peripheral TCL) } \\
\text { Hodgkin lymphoma }\end{array}$ \\
\hline & Solid cancer & $\begin{array}{l}\text { Adenocarcinoma (lung and } \\
\text { digestive tract) } \\
\text { Cervical cancer }\end{array}$ \\
\hline
\end{tabular}

SELECTED OTHER CAUSES

Autoimmune disorders/ vasculitis/other immune dysregulatory disorders

Primary immunodeficiencies

Miscellaneous

Hypereosinophilic syndromes

${ }^{*}$ As defined in table 1.

tEosinophilia is most often below $1.5 \mathrm{~g} / \mathrm{L}$ in these disorders but may reach that threshold in severe cases.

LOF, loss of function; STAT, signal transducer and activator of transcription; TCL, T-cell lymphoma.

clear relationship between the occurrence and severity of cardiac involvement and that of general or other organ-based symptoms.

Given the absence of specific evidence-based consensus for risk stratification of HES-cardiomyopathy, general recommendations for myocarditis, valvular heart disease and HF should be followed, ${ }^{17-20}$ with special attention to the prevention of sudden cardiac death and thromboembolic events. ${ }^{21}$ To detect cardiac damage, a stepwise approach using multimodality imaging should be applied, driven by the patient's complaints and cardiovascular events when present (figures 1 and 2). Imaging studies should be completed by blood biomarkers and functional assessment, and in some instances, EMB is required for definitive proof of eosinophil-mediated heart disease.

\section{Echocardiography}

In daily practice, echocardiography remains the key exam to detect HES-related cardiac complications. Myocardial damage predominantly affects subendocardial tissue, and already in the early inflammatory/necrotic stage, increased subendocardial echogenicity should raise attention. ${ }^{22}$ A combination of left ventricular (LV) dysfunction and intracardiac thrombi can be seen prior to development of fibrosis (figure 1). ${ }^{123}$ The thrombi are usually located at the apex or the subvalvular regions of atrioventricular (AV) valves, while the outflow tracts are generally spared. Both ventricles may be affected, and LV mass may be increased, leading to high filling pressures and impaired diastolic function. In later stages, thrombi can organise as intraventricular or valvular vegetations (defining Loeffler's endocarditis). Valvular damage is common and may be the consequence of fibrotic valvular thickening and/or impaired mobility of the subvalvular apparatus, leading most frequently to AV-valve regurgitation. In rare cases, aortic or mitral stenosis can occur as a consequence of valve thickening and fibrosis. ${ }^{24}$ Severity of endomyocardial fibrosis can be quantified using a scoring system (table 4). ${ }^{22}$

Conventional transthoracic echocardiography may be completed by contrast injection for improved visualisation of apical thrombi and for differential diagnosis of ventricular masses. $^{25}$ Transoesophageal echocardiography allows a better definition of valvular involvement and atrial thrombus detection. ${ }^{25}$ When present, endomyocardial fibrosis generates a restrictive physiology, although progression to dilated cardiomyopathy (DCM) may be observed. Strain imaging can help in the differential diagnosis between HES and other causes of restrictive cardiomyopathy. ${ }^{26}$

\section{Cardiac Magnetic Resonance Imaging}

Cardiac magnetic resonance (CMR) combined with contrastenhanced imaging is currently the most sensitive non-invasive tool, allowing detailed tissue characterisation at all stages of disease.

Diagnosis of myocarditis is based on Lake Louis criteria describing late-enhancement sequences (fibrosis), T2-weighted acquisitions (oedema) and T1-weighted sequences before and after contrast injection (early enhancement and hyperaemia). ${ }^{27}$ Using these criteria, we found that CMR has an approximate sensitivity of $55 \%-60 \%$ for detection of inflammatory cardiomyopathy as compared with biventricular biopsy used as a gold standard. ${ }^{28}$ In patients with HES, CMR is more sensitive than echocardiography to detect inflammation and thrombus: late gadolinium enhancement (LGE) is typically subendocardial but can affect the entire thickness of the myocardium. ${ }^{22} 29$

Recently, new cardiac CMR sequences like T1 mapping and extracellular volume (ECV) quantification have emerged as promising tools to better define myocardial fibrosis and oedema, allowing a spectral-based differential diagnosis. ${ }^{30}$ Overall and in the particular case of HES, the role of T1 mapping and ECV quantification has still to be defined, but those sequences appear promising to improve the detection and quantification of cardiac inflammation and fibrosis.

Based on its higher sensitivity as compared with echocardiography, CMR is required to efficiently detect cardiac inflammation in patients with HES, even in the absence of cardiovascular symptoms and with normal echocardiography. Follow-up studies showed regression of subendocardial LGE on treatment, suggesting that repeated CMR could be justified in selected patients to assess disease activity and treatment response. ${ }^{31} 32$ Nevertheless, clinicians should keep in mind that CMR does not detect all cases of eosinophilic cardiomyopathy, even when using modern acquisition methods. 


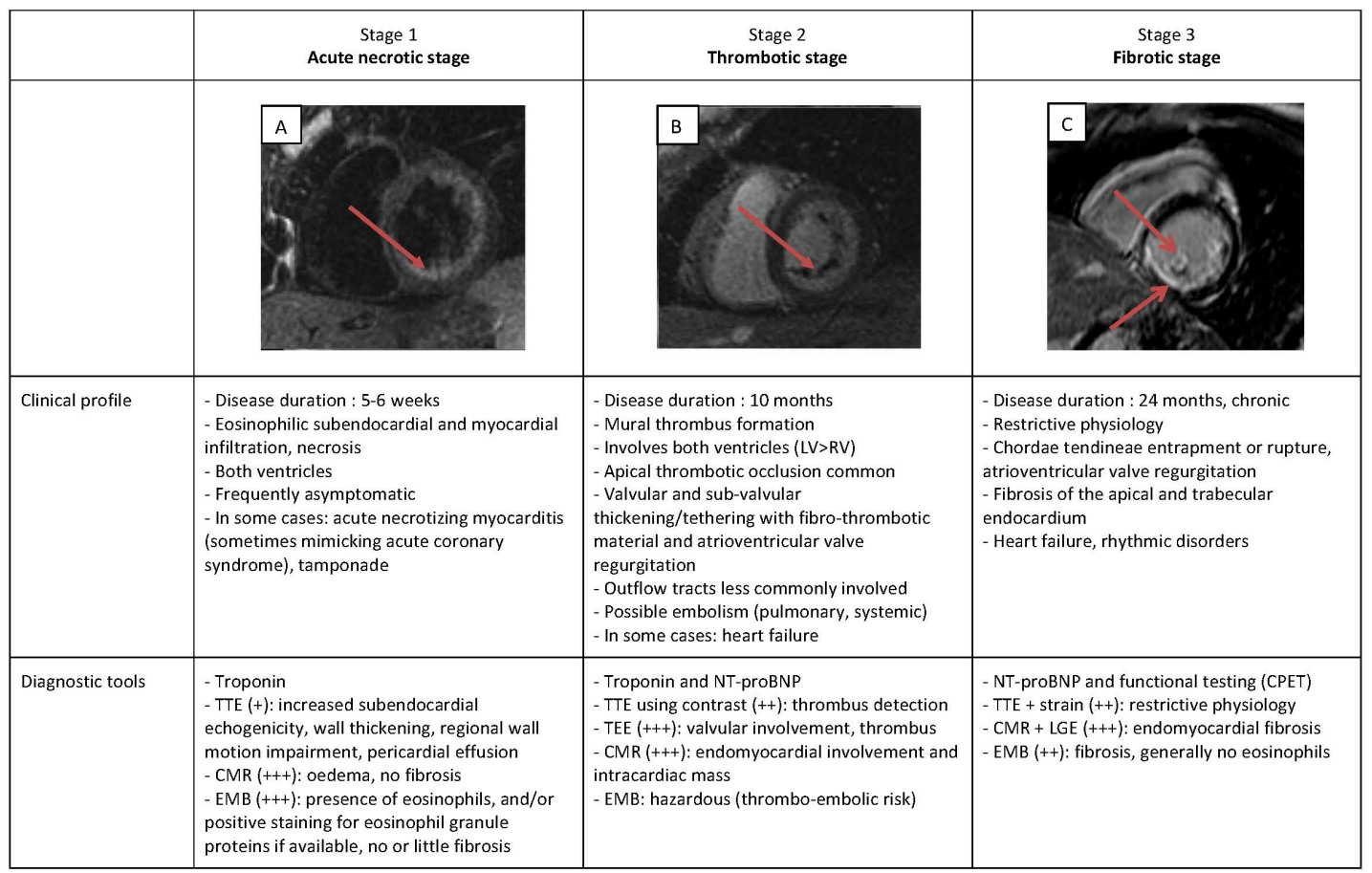

Figure 1 Cardiac involvement in HES. Schematic representation of the main CMR and clinical findings in HES related to the stage, and corresponding diagnostic investigations. (A) CMR short-axis view showing marked increase in T2 signal involving anterior, lateral and inferior walls of the left ventricle, suggesting oedema (arrow). (B) CMR short-axis view of delayed enhancement imaging showing hyperenhancement involving the subendocardial region with associated non-enhancing thrombus along the subendocardial surface (arrow). (C) CMR short-axis view showing LV inferior wall and papillary muscle fibrosis as detected by intramural late gadolinium enhancement (arrows). (A,B) Reproduced from Mankad et al (with permission). ${ }^{37} \mathrm{CMR}$, cardiac magnetic resonance; CPET, cardiopulmonary exercise testing; EMB, endomyocardial biopsy; HES, hypereosinophilic syndrome; LV, left ventricul; NT-proBNP, N-terminal pro-brain natriuretic peptide; RV, right ventricul; TEE, transoesophageal echocardiography; TTE, transthoracic echocardiography.

\section{Endomyocardial biopsy remains the gold standard}

Endomyocardial biopsy (EMB), or pathological analysis of a surgical sample, remains the gold standard for diagnosis of eosinophilic cardiomyopathy, showing presence of eosinophils and/or their granule products in cardiac tissue. The threshold for performing cardiac biopsy should be lowered. Indeed, in a retrospective review of 288 HES cases, echocardiography and EMB coincided in only $60 \%$ of the cases, and positive EMBs were obtained in seven patients with a normal echocardiography. ${ }^{33}$ Generally speaking, EMB is recommended when inflammatory

Table 3 Pathogenic mechanisms involved in eosinophil-mediated heart damage and coagulation

\begin{tabular}{|c|c|c|}
\hline Mediator-mechanism & Model-experimental setting & Observations-mechanisms \\
\hline \multicolumn{3}{|l|}{ CYTOTOXICITY } \\
\hline Not investigated & $\begin{array}{l}\text { Cat papillary muscle in vitro incubated with eosinophils or eosinophil } \\
\text { supernatants from patients with HES and healthy controls }\end{array}$ & $\begin{array}{l}\text { Eosinophils and supernatants from patients with HES only induced marked } \\
\text { ultrastructural alterations, with appearance of holes in EC membranes, cellular } \\
\text { retraction and exposure of the underlying basal membrane }\end{array}$ \\
\hline MBP & Porcine aortic EC grown to confluence in vitro and incubated with MBP & $\begin{array}{l}\text { Destruction of EC at MBP concentrations similar to those observed in serum } \\
\text { from hypereosinophilic patients }\end{array}$ \\
\hline EPX & $\begin{array}{l}\text { Several types of EC and isolated working rat hearts incubated in vitro with } \\
\text { activated eosinophils and purified human EPX }\end{array}$ & $\begin{array}{l}\text { Oxidation of bromide to hypobromous acid in the presence of } \mathrm{H}_{2} \mathrm{O}_{2} \text {, leading to } \\
\text { bromide-dependent destruction of } \mathrm{EC}\end{array}$ \\
\hline \multicolumn{3}{|l|}{ COAGULATION } \\
\hline TF & $\begin{array}{l}\text { Human BM preparations and blood: immunoelectron microscopy, RT-PCR, flow } \\
\text { cytometry }\end{array}$ & $\begin{array}{l}\text { 1. Expressed by activated eosinophils. } \\
\text { 2. Eosinophil-induced damage to ECs (see previous items) exposes underlying } \\
\text { TF. } \\
\text { TF triggers extrinsic coagulation pathway }\end{array}$ \\
\hline CD40L-CD40 interactions & $\begin{array}{l}\text { In vitro-activated eosinophils from healthy humans and EOL-3 cell line, ex vivo } \\
\text { eosinophils from patient with HES: flow cytometry, RT-PCR, northern blot }\end{array}$ & $\begin{array}{l}\text { CD40L upregulated on activated eosinophils } \\
\text { Interacts with EC-expressed CD40 }\end{array}$ \\
\hline MBP, EPX & $\begin{array}{l}\text { Cationic proteins purified from blood eosinophils of patients with HES } \\
\text { incubated in vitro with purified platelets }\end{array}$ & $\begin{array}{l}\text { 1. Bind to (anionic) thrombomodulin and interfere with its natural } \\
\text { anticoagulant activity. } \\
\text { 2. Direct activation of platelets. }\end{array}$ \\
\hline EPX & $\begin{array}{l}\text { Human umbilical vein EC cultures exposed in vitro to oxidants known to be } \\
\text { produced by different phagocytes }\end{array}$ & $\begin{array}{l}\text { Oxidation of thiocyanate to hypothiocyanous acid ( } \mathrm{HOSCN} \text { ) in presence of } \mathrm{H}_{2} \mathrm{O}_{2} \text {, } \\
\text { leading to TF expression by ECS }\end{array}$ \\
\hline
\end{tabular}




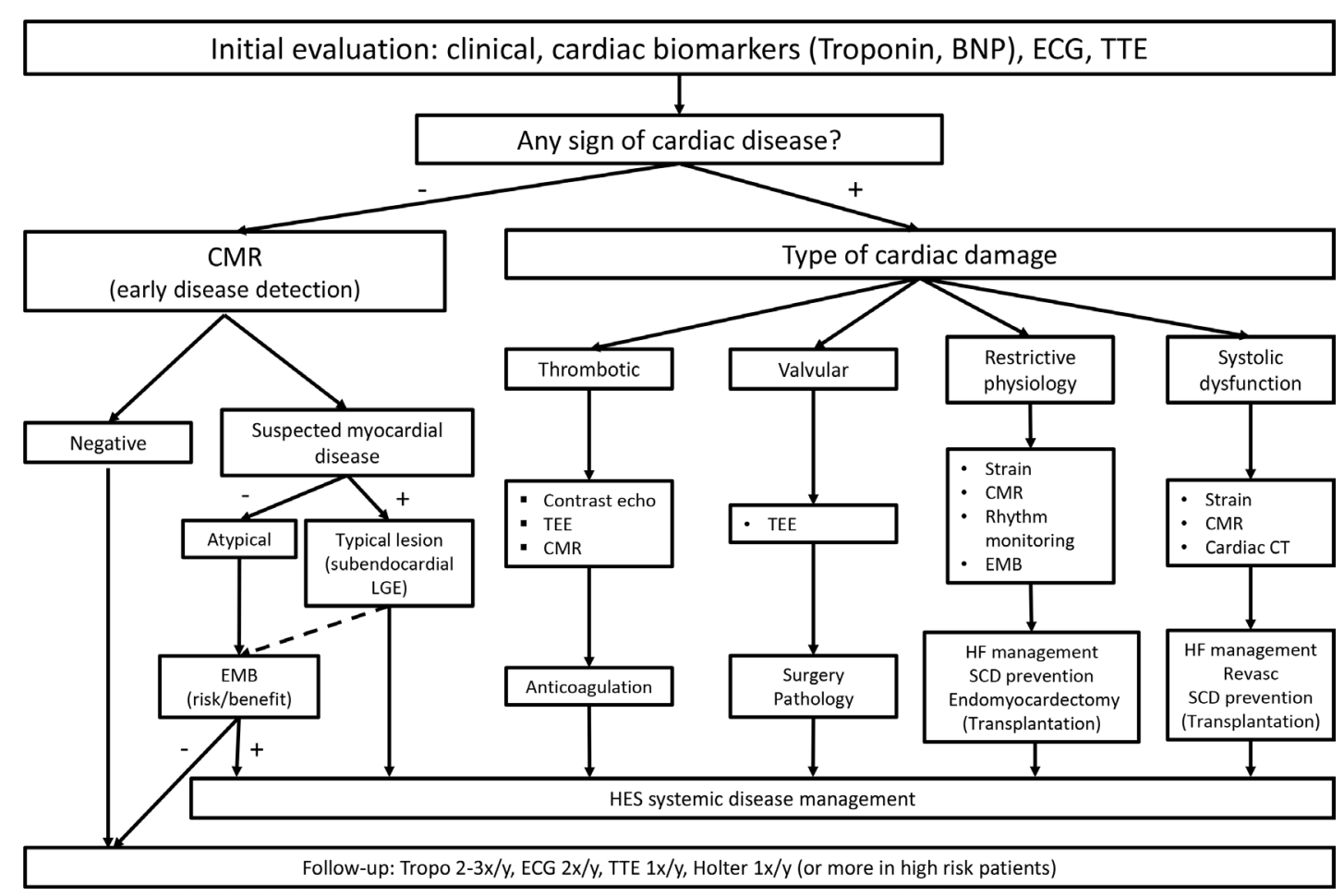

Figure 2 Approach to investigation of cardiac involvement in a patient presenting with persistent HE. This figure shows a proposed algorithm for the initial cardiac evaluation of a patient presenting with persistent $\mathrm{HE}$, whether symptoms are present or not, and regardless of evidence for involvement of other organ systems, reflecting the authors' personal approach. It should be noted that the decision to perform an EMB is always made on a case-by-case basis, integrating the likelihood it will be contributive on one hand, and the risk incurred by the patient in the setting of existing comorbidities on the other. When installed restrictive cardiomyopathy is present, pathology may be non-specific, showing fibrosis in absence of eosinophilic infiltrates. BNP, brain natriuretic peptide; CMR, cardiac magnetic resonance; EMB, endomyocardial biopsy; $\mathrm{HE}$, hypereosinophilia; $\mathrm{HF}$, heart failure; LGE, late gadolinium enhancement; TEE, transoesophageal echocardiography; TTE, transthoracic echocardiography.

cardiac disease is suspected. ${ }^{17} 18$ Of note, in the acute phase, eosinophils may (rarely) be present in cardiac tissue in the absence of circulating HE, possibly related to intense eosinophil

\begin{tabular}{|c|c|}
\hline & Score \\
\hline \multicolumn{2}{|l|}{ Major criteria } \\
\hline Endomyocardial plaques $>2 \mathrm{~mm}$ in thickness & 2 \\
\hline $\begin{array}{l}\text { Thin }(<1 \mathrm{~mm}) \text { endomyocardial patches affecting more than one ventricular } \\
\text { wall }\end{array}$ & 3 \\
\hline Obliteration of the RV or LV apex & 4 \\
\hline Thrombi or spontaneous contrast without severe ventricular dysfunction & 4 \\
\hline Retraction of the RV apex & 4 \\
\hline $\begin{array}{l}\text { Atrioventricular valve dysfunction due to adhesion of the valvular } \\
\text { apparatus to the ventricular wall (according to severity of the mitral } \\
\text { regurgitation) }\end{array}$ & $1-4$ \\
\hline \multicolumn{2}{|l|}{ Minor criteria } \\
\hline Thin endomyocardial patches localised to one ventricular wall & 1 \\
\hline Restrictive flow pattern across mitral or tricuspid valve & 2 \\
\hline Pulmonary valve diastolic opening & 2 \\
\hline Diffuse thickening of the anterior mitral leaflet & 1 \\
\hline Enlarged atrium with normal-sized ventricle & 2 \\
\hline $\begin{array}{l}\text { M-movement of septum related to obliteration or restriction of the LV } \\
\text { apex (in combination with mitral regurgitation) }\end{array}$ & 1 \\
\hline Hyperechogenicity of the moderator band or other bands & 1 \\
\hline \multicolumn{2}{|c|}{$\begin{array}{l}\text { The diagnosis of endomyocardial fibrosis is established in the presence of two major criteria } \\
\text { or one major criteria with two minor criteria. Disease severity can be assessed: less than } 8 \\
\text { defining mild disease, 8-15 moderate disease and }>15 \text { severe disease (reproduced from } \\
\text { Kleinfeldt et al, with permission).22 } \\
\text { LV, left ventricular; RV, right ventricular. }\end{array}$} \\
\hline
\end{tabular}

activation and chemotaxis. ${ }^{34}$ In order to improve sensitivity and to allow a better characterisation of cellular infiltrates, immunohistochemistry and immunofluorescence directed against eosinophil-specific proteins should be used when possible. ${ }^{17}$ Reverse transcription PCR and molecular signatures through RNA sequencing could complete this approach. Detection of myocardial fibrosis is also a key element, although apart from its subendocardial localisation, this finding is not specific for HES-cardiomyopathy.

In clinical practice, the decision to perform EMB should always be patient-centred after careful assessment of the risk:benefit ratio. ${ }^{356}$ The 2013 European Society of Cardiology (ESC) consensus documents recommend its use to confirm the diagnosis of myocarditis, with a high level of recommendation in case of life-threatening disease. ${ }^{1736}$ In the same line, the 2007 AHA scientific statement provided a level IIa-C recommendation for EMB in case of unexplained DCM associated with a suspected allergic reaction and/or eosinophilia, in order to rule out a potentially treatable underlying disease like HES. ${ }^{18}$

\section{ECG and rhythmic monitoring}

Although ECG is classically a first-line exam in cardiological work-up, anomalies are present in less than one-third of patients with HES. ${ }^{37}$ Ventricular extrasystoly is frequent, and in some cases, Loeffler endocarditis can present with polymorphic ventricular tachycardia. ${ }^{38} \mathrm{~A}$ careful rythmological evaluation should be performed in patients with HES in the presence of palpitations, ventricular ectopic beats or unexplained syncope, as well as those with severe LV dysfunction or restrictive cardiomyopathy. 
Holter ECG is useful to detect cardiac arrhythmia, although its sensitivity is limited. ${ }^{39}$ In selected patients, electrophysiological evaluation and loop recorder implantation may be performed for more accurate rhythmic risk stratification.

\section{Serum biomarkers}

Blood eosinophilia is an obvious parameter that must raise suspicion of underlying eosinophil-mediated damage in a patient with cardiac manifestations. Serum troponin is a useful marker for detection and follow-up of cardiac disease activity in the acute phase of HES. Elevated levels may reflect myocardial damage, vascular damage and/or HF. When eosinophilic cardiomyopathy develops in the absence of blood HE, troponin measurement could replace serial blood eosinophil counts to monitor treatment response. ${ }^{40}$ Furthermore, this biomarker is used to identify patients with FIP1L1-PDGFRA ${ }^{+}$HES $_{N}$ at risk of development of acute HF during the first few days of treatment with the tyrosine kinase inhibitor imatinib mesylate. ${ }^{41}$

Classical markers of $\mathrm{HF}$, particularly N-terminal pro-brain natriuretic peptide, must be assessed in patients presenting with HES-cardiomyopathy for diagnosis and follow-up. ${ }^{20}$ Other new markers such as ST2 appear promising for risk stratification in patients with $\mathrm{HF}^{42}$ but their role in HES management has yet to be defined. Measurement of eosinophil-specific mediators like eosinophil cationic protein and major basic protein in serum to evaluate the degree of eosinophil activation in vivo ${ }^{43}$ is technically challenging and has not been validated in this setting.

\section{Cardiac CT and nuclear imaging}

Cardiac CT imaging is useful for detection of coronary aneurysms which may be associated with $\mathrm{HE},{ }^{44}$ as well as thrombotic complications, offering an alternative to CMR for patients in whom this procedure is contraindicated.

Combined with CMR, nuclear imaging using fluorodeoxyglucose, fibrosis-specific or eosinophil protein specific tracers could represent new avenues for future characterisation of HESmediated cardiomyopathy.

\section{CLINICAL MANAGEMENT OF HEART INVOLVEMENT IN PATIENTS WITH HES}

Given the wide spectrum of clinical presentations of eosinophilic cardiomyopathy, patient management should be tailored to his/her condition. The general rule is that circulating eosinophil counts should be lowered, ideally below $0.6 \mathrm{G} / \mathrm{L}$, with the appropriate therapeutic agents, ${ }^{45}$ to block disease progression and to prevent development of myocardial fibrosis. Corticosteroids represent the cornerstone of treatment in the majority of cases, with the exception of patients with FIP1L1-PDGFRA ${ }^{+}$ HES $_{\mathrm{N}}$ who respond remarkably well to imatinib mesylate. The other treatment options, typically combined with corticosteroids in patients who need high dosing regimens for disease control (as CS-sparing agents) or administered sequentially in CS-resistant subjects, include hydoxyurea, interferon-alpha, cyclosporine, methotrexate, alemtuzumab and just recently approved mepolizumab. ${ }^{46}$ Rare patients with treatment-refractory disease may even require allogeneic stem cell transplantation. Detailed treatment of HES according to clinical presentation and variants has been reviewed elsewhere. ${ }^{45}$ Patients should be referred to a specialist with expertise in HES for general management. However, in the presence of cardiac involvement, it is critical that cardiologists contribute actively to the more specific aspects related to management of these complications.

\section{Heart failure management}

Patients with HES that develop congestive HF should be managed according to general recommendations on $\mathrm{HF}^{20}$ In the acute phase, high-dose CS therapy improves outcome and should be initiated rapidly. Cardiogenic shock requires inotropic support, and mechanical circulatory support is an option in refractory cases: authors have reported successful use of biventricular assist device in this situation. ${ }^{47}$ One case of cardiac transplantation in fulminant acute myocarditis has also been reported. ${ }^{48}$

\section{Thromboembolic complications}

Anticoagulation is indicated in patients with confirmed intracavitary thrombus and/or recurrent thromboembolic events, as well as after cardiac valve surgery. Vitamin $\mathrm{K}$ antagonists (VKAs) remain the standard of care in intraventricular thrombus management. Although use of direct oral anticoagulants has been suggested as an alternative, they should be used with caution as no data are available for HES-cardiomyopathy. ${ }^{49}$ Associating VKA with antiplatelet therapy has also been suggested by some authors, ${ }^{5051}$ but the utility of this association is unknown. It is generally accepted that the duration of anticoagulation should be tailored to HES and endomyocardial disease activity, although there are no clear data supporting this.

\section{Valvular heart disease}

Valvular disease is frequent in HES-cardiomyopathy, most commonly consisting in AV valve regurgitation. In the absence of specific data, indications for valvular surgery should follow general guidelines. ${ }^{19} 52$ The most commonly reported procedure is mitral valve replacement. Pathological assessment of resected valvular tissue is of prime importance, as the diagnosis of eosinophil-mediated cardiomyopathy can be confirmed on the surgical specimen. In patients with HES, the choice between mechanical and biological valves can be challenging: while mechanical valves are associated with a high risk of recurrent thrombosis, biological valves are likely to have shorter longevity in this inflammatory condition. ${ }^{51}$ Cases of bioprosthesis thrombosis have been reported in HES, justifying lifelong anticoagulation with VKA after surgery, even after biological valve replacement.

When technically feasible, valvular repair is the preferred option and should be performed in expert centres, as this procedure is associated with fewer thrombotic events than valve replacement. Importantly, efforts should be made to ensure optimal medical treatment to control underlying disease following valvular surgery, as persistent $\mathrm{HE}$ is associated with poor outcome and rapid valve degeneration.

\section{Rythmic disorders and sudden cardiac death}

Inflammation, fibrosis, ischaemia and valvular disease are the substrates for rhythmic disorders in HES-cardiomyopathy, ranging from benign supraventricular arrhythmias to sudden cardiac death in the setting of ventricular arrhythmias. An implantable cardiac defibrillator should be placed as primary or secondary prevention according to current guidelines, adapting the threshold to global disease control, ejection fraction and fibrosis extension. ${ }^{21}$

\section{Advanced care and heart transplantation}

In the presence of advanced restrictive cardiomyopathy, surgical resection of fibrotic endocardium (endomyocardectomy) has been shown to improve 5 -year survival compared with medical treatment alone, and combined with resection of organised 
thrombotic masses, this approach can improve diastolic function and symptoms. ${ }^{53-55}$ In case of end-stage HF and/or recurrent valve thrombosis despite optimal management, orthotopic heart transplantation is an option that has produced favourable outcomes in case reports. ${ }^{48}$

In conclusion, although detection and treatment of HESassociated cardiopathy have improved considerably, many unmet needs remain. These include the identification of biomarkers and/or clinical characteristics associated with an increased risk for this complication, the significance of elevated troponin and/or abnormal imaging studies in asymptomatic patients, the extent to which eosinophil counts must be depleted by treatment to prevent further progression, and the most appropriate investigations to assess cardiac disease activity over time. Prospective studies on large multicentre cohorts to address these questions are required, as well as multidisciplinary management, actively engaging cardiologists in early diagnosis and follow-up, to further improve patient outcome.

Contributors $A B, F R$ and $C C$ contributed equally to the writing and the review of the article.

Funding FNRS (Belgian National Fund for Scientific Research) grant number J.0011.19F (AB) and F 5/4/150/5 (FR). AB is coholder of an Actelion Chair for Research in Pulmonary Hypertension. ULB Fonds Erasme (CC).

Competing interests $A B$ has received consultancy fees from Amicus, Baeyer, Boehringer Ingelheim, Sanofi, Pfizer, Novartis and Alnylam; speaker fees from Pfizer, Sanofi and Alnylam. FR has received consultancy fees from GlaxoSmithKline and AstraZeneca for expertise in hypereosinophilic syndromes and royalties from UpToDate.

Patient and public involvement Patients and/or the public were not involved in the design, conduct, reporting or dissemination plans of this research.

Patient consent for publication Not required.

Provenance and peer review Commissioned; externally peer reviewed.

ORCID iDs

Antoine Bondue http://orcid.org/0000-0002-4103-515X

Florence Roufosse http://orcid.org/0000-0002-5288-0375

\section{REFERENCES}

1 Klion AD, Ackerman SJ, Bochner BS. Contributions of eosinophils to human health and disease. Annu Rev Pathol 2020;15:179-209.

2 Valent P, Klion AD, Horny H-P, et al. Contemporary consensus proposal on criteria and classification of eosinophilic disorders and related syndromes. J Allergy Clin Immunol 2012:130:607-12.

3 Chusid MJ, Dale DC, West BC, et al. The hypereosinophilic syndrome: analysis of fourteen cases with review of the literature. Medicine 1975;54:1-27.

4 Ogbogu PU, Bochner BS, Butterfield JH, et al. Hypereosinophilic syndrome: a multicenter, retrospective analysis of clinical characteristics and response to therapy. $J$ Allergy Clin Immunol 2009;124:1319-25.

5 Legrand F, Renneville A, Macintyre E, et al. The spectrum of FIP1L1-PDGFRAassociated chronic eosinophilic leukemia: new insights based on a survey of 44 cases. Medicine 2013:92:e1-9.

6 Carpentier C, Verbanck S, Schandené L, et al. Eosinophilia Associated With CD3 ${ }^{-} \mathrm{CD} 4^{+}$ T Cells: Characterization and Outcome of a Single Center Cohort of 26 Patients. Front Immunol 2020;11:11.

7 Parrillo JE, Borer JS, Henry WL, et al. The cardiovascular manifestations of the hypereosinophilic syndrome. prospective study of 26 patients, with review of the literature. Am J Med 1979;67:572-82.

8 Cools J, DeAngelo DJ, Gotlib J, et al. A tyrosine kinase created by fusion of the PDGFRA and FIP1L1 genes as a therapeutic target of imatinib in idiopathic hypereosinophilic syndrome. N Eng/ J Med 2003;348:1201-14.

9 Harley JB, Fauci AS, Gralnick HR. Noncardiovascular findings associated with heart disease in the idiopathic hypereosinophilic syndrome. Am J Cardiol 1983;52:321-4.

10 Bletry O, Scheuble C, Cereze P, et al. [Cardiac manifestations of the hypereosinophilic syndrome. The value of 2-dimensional echography (12 cases)]. Arch Mal Coeur Vaiss 1984;77:633-41.

11 Podjasek JC, Butterfield JH. Mortality in hypereosinophilic syndrome: 19 years of experience at Mayo clinic with a review of the literature. Leuk Res 2013;37:392-5.
12 Fauci AS, Harley JB, Roberts WC, et al. NIH conference. The idiopathic hypereosinophilic syndrome. Clinical, pathophysiologic, and therapeutic considerations. Ann Intern Med 1982;97:78-92.

13 Corradi D, Vaglio A, Maestri R, et al. Eosinophilic myocarditis in a patient with idiopathic hypereosinophilic syndrome: insights into mechanisms of myocardial cell death. Hum Pathol 2004;35:1160-3.

14 Tai PC, Ackerman SJ, Spry CJ, et al. Deposits of eosinophil granule proteins in cardiac tissues of patients with eosinophilic endomyocardial disease. Lancet 1987;1:643-7.

15 Roufosse F. L4. eosinophils: how they contribute to endothelial damage and dysfunction. Presse Med 2013:42:503-7.

16 Séguéla P-E, Iriart X, Acar P, et al. Eosinophilic cardiac disease: molecular, clinical and imaging aspects. Arch Cardiovasc Dis 2015;108:258-68.

17 Caforio ALP, Pankuweit S, Arbustini E, et al. Current state of knowledge on aetiology, diagnosis, management, and therapy of myocarditis: a position statement of the European Society of cardiology Working group on myocardial and pericardial diseases. Eur Heart J 2013;34:2636-48.

18 Cooper LT, Baughman KL, Feldman AM, et al. The role of endomyocardial biopsy in the management of cardiovascular disease: a scientific statement from the American Heart Association, the American College of Cardiology, and the European Society of Cardiology. Circulation 2007;116:2216-33.

19 Baumgartner H, Falk V, Bax JJ, et al. 2017 ESC/EACTS guidelines for the management of valvular heart disease. Eur Heart J 2017;38:2739-91.

20 Ponikowski P, Voors AA, Anker SD, et al. 2016 ESC guidelines for the diagnosis and treatment of acute and chronic heart failure: the task force for the diagnosis and treatment of acute and chronic heart failure of the European Society of Cardiology (ESC). developed with the special contribution of the Heart Failure Association (HFA) of the ESC. Eur J Heart Fail 2016:18:891-975.

21 Priori SG, Blomström-Lundqvist C, Mazzanti A, et al. 2015 ESC guidelines for the management of patients with ventricular arrhythmias and the prevention of sudden cardiac death: the task force for the management of patients with ventricular arrhythmias and the prevention of sudden cardiac death of the European Society of Cardiology (ESC). endorsed by: Association for European Paediatric and Congenital Cardiology (AEPC). Eur Heart J 2015;36:2793-867.

22 Kleinfeldt T, Nienaber CA, Kische S, et al. Cardiac manifestation of the hypereosinophilic syndrome: new insights. Clin Res Cardiol 2010;99:419-27.

23 Gottdiener JS, Maron BJ, Schooley RT, et al. Two-dimensional echocardiographic assessment of the idiopathic hypereosinophilic syndrome. anatomic basis of mitral regurgitation and peripheral embolization. Circulation 1983;67:572-8.

24 Eicher J-C, Bonnotte B, L'huillier I, et al. [Cardiovascular manifestations of eosinophilia: clinical and echocardiographic presentation]. Rev Med Interne 2009;30:1011-9.

25 Shah R, Ananthasubramaniam K. Evaluation of cardiac involvement in hypereosinophilic syndrome: complementary roles of transthoracic, transesophageal, and contrast echocardiography. Echocardiography 2006;23:689-91.

26 Eroglu E, Di Salvo G, Herbots L, et al. Restrictive left ventricular filling in hypereosinophilic syndrome as a result of partial cavity obliteration by an apical mass: a strain/strain rate study. J Am Soc Echocardiogr 2003;16:1088-90.

27 Friedrich MG, Sechtem U, Schulz-Menger J, et al. Cardiovascular magnetic resonance in myocarditis: a JACC white paper. J Am Coll Cardiol 2009;53:1475-87.

28 Yilmaz A, Kindermann I, Kindermann M, et al. Comparative evaluation of left and right ventricular endomyocardial biopsy: differences in complication rate and diagnostic performance. Circulation 2010;122:900-9.

29 Pillar N, Halkin A, Aviram G. Hypereosinophilic syndrome with cardiac involvement: early diagnosis by cardiac magnetic resonance imaging. Can J Cardiol 2012;28:515 e11-3.

30 Messroghli DR, Moon JC, Ferreira VM, et al. Clinical recommendations for cardiovascular magnetic resonance mapping of $\mathrm{T} 1, \mathrm{~T} 2, \mathrm{~T}^{*}$ and extracellular volume: a consensus statement by the Society for cardiovascular magnetic resonance (SCMR) endorsed by the European association for cardiovascular imaging (EACVI). $J$ Cardiovasc Magn Reson 2017;19:75.

31 Cheung SCW, Chan CWS. Insights of prognostication of Davies disease: what could we learn from serial magnetic resonance imaging studies? Int I Cardiol 2010;142:e32-4.

32 Debl K, Djavidani B, Buchner S, et al. Time course of eosinophilic myocarditis visualized by CMR. J Cardiovasc Magn Reson 2008;10:21.

33 Butterfield JH, Kane GC, Weiler CR. Hypereosinophilic syndrome: endomyocardial biopsy versus echocardiography to diagnose cardiac involvement. Postgrad Med 2017;129:517-23.

34 Aslan I, Fischer M, Laser KT, et al. Eosinophilic myocarditis in an adolescent: a case report and review of the literature. Cardiol Young 2013;23:277-83.

35 Tschöpe C, Cooper LT, Torre-Amione G, et al. Management of Myocarditis-Related cardiomyopathy in adults. Circ Res 2019;124:1568-83.

36 Heymans S, Eriksson U, Lehtonen J, et al. The Quest for New Approaches in Myocarditis and Inflammatory Cardiomyopathy. J Am Coll Cardiol 2016;68:2348-64.

37 Mankad R, Bonnichsen C, Mankad S. Hypereosinophilic syndrome: cardiac diagnosis and management. Heart 2016;102:100-6. 
38 Coelho-Filho OR, Mongeon F-P, Mitchell RN, et al. Images in cardiovascular medicine. Löffler endocarditis presenting with recurrent polymorphic ventricular tachycardia diagnosed by cardiac magnetic resonance imaging. Circulation 2010;122:96-9.

39 Cohen J, Davies J, Goodwin JF, et al. Arrhythmias in patients with hypereosinophilia: a comparison of patients with and without Löffler's endomyocardial disease. Postgrad Med J 1980;56:828-32.

40 Kakino T, Yokoyama H, Eshima K. Significance of troponin I level as a marker of disease activity in the management of acute necrotizing eosinophilic myocarditis with normal peripheral eosinophil count: a case report. Eur Heart J Case Rep 2018;2:yty139.

41 Pitini V, Arrigo C, Azzarello D, et al. Serum concentration of cardiac troponin T in patients with hypereosinophilic syndrome treated with imatinib is predictive of adverse outcomes. Blood 2003;102:3456-7.

42 Mebazaa A, Di Somma S, Maisel AS, et al. ST2 and multimarker testing in acute decompensated heart failure. Am J Cardiol 2015:115:38B-43.

43 Arima M, Kanoh T. Eosinophilic myocarditis associated with dense deposits of eosinophil cationic protein (ECP) in endomyocardium with high serum ECP. Heart 1999;81:669-71.

44 Divanji P, Deo R, Harris I. Coronary arteries and the cell count. Circulation 2019;139:1228-33.

45 Klion AD. How I treat hypereosinophilic syndromes. Blood 2015;126:1069-77.

46 Roufosse F, Kahn J-E, Rothenberg ME, et al. Efficacy and safety of mepolizumab in hypereosinophilic syndrome: A phase III, randomized, placebo-controlled trial. J Allergy Clin Immunol 2020;146:1397-405.
47 Cooper LT, Zehr KJ. Biventricular assist device placement and immunosuppression as therapy for necrotizing eosinophilic myocarditis. Nat Clin Pract Cardiovasc Med 2005;2:544-8.

48 Korczyk D, Taylor G, McAlistair H, et al. Heart transplantation in a patient with endomyocardial fibrosis due to hypereosinophilic syndrome. Transplantation 2007;83:514-6.

49 Robinson A, Ruth B, Dent J. Direct oral anticoagulants compared to warfarin for left ventricular thrombi: a single center experience. J Am Coll Cardiol 2018;71:A981-A.

50 Terrier B, Piette A-M, Kerob D, et al. Superficial venous thrombophlebitis as the initial manifestation of hypereosinophilic syndrome: study of the first 3 cases. Arch Dermatol 2006;142:1606-10.

51 Ogbogu PU, Rosing DR, Horne MK. Cardiovascular manifestations of hypereosinophilic syndromes. Immunol Allergy Clin North Am 2007;27:457-75.

52 Otto CM, Nishimura RA, Bonow RO, et al. 2020 ACC/AHA guideline for the management of patients with valvular heart disease: a report of the American College of Cardiology/American Heart Association Joint Committee on Clinical Practice Guidelines. Circulation 2020:CIR0000000000000923.

53 Lepley D, Aris A, Korns ME, et al. Endomyocardial fibrosis. A surgical approach. Ann Thorac Surg 1974;18:626-33.

54 Moraes F, Lapa C, Hazin S, et al. Surgery for endomyocardial fibrosis revisited. Eur J Cardiothorac Surg 1999;15:309-13.

55 Schneider U, Jenni R, Turina J, et al. Long-term follow up of patients with endomyocardial fibrosis: effects of surgery. Heart 1998;79:362-7. 